\title{
Las cláusulas abusivas en el derecho privado colombiano
}

\section{Diego Ornar Pérez Salas}

Abogado de la Universidad del Cauca. Especialista en Derecho Contractual y Relaciones Jurídico Negóciales de la Universidad Externado de Colombia, Diplomado en Derecho del Trabajo, por la Universidad Complutense de Madrid (España), candidato a Magíster en Responsabilidad Civil y del Estado en la Universidad Externado de Colombia, profesor de medio tiempo en el programa de Derecho de la Universidad Surcolombiana de Neiva.

\section{Resumen}

Las cláusulas abusivas constituyen el paradigma de protección a la parte débil en el derecho contractual moderno. Este instrumento es considerado como una protección formal ya que pone un límite en el proceso de formación del contrato. Este tipo de cláusulas ha presentado un desarrollo legal y doctrinal considerable en el derecho comparado, pero bastante escaso por no decir nulo, en el derecho colombiano. Estas cláusulas abusivas o vejatorias han sido tratadas por la jurisprudencia de la Corte Suprema de Justicia partiendo del principio general de la prohibición del abuso del derecho, buscando con ello brindar protección a la parte contratante afectada por un acuerdo que finalmente se juzgue como abusivo.

\section{Palabras claves}

Cláusulas abusivas, Principio de la autonomía de la voluntad privada, contratos, libertad contractual, abuso del derecho.

\section{Abstract}

The improper clauses are the most of protection to the week part in modern contractual law. This instrument is considered as a formal protection because it puts a border on the contract formation process. This kind of clauses has had a considerable legal and doctrinal development in comparative law, but quite scarce, or rather null and void, in Colombian law. This improper or vexation clauses have been treated by the jurisprudence of the Supreme of Justice Court beginning from the general principle of the prohibition of the right abuse, looking for giving to the affected dealer by an agreement that finally would be judged as improper. 


\section{Introducción}

A bordar el tema de las cláusulas abusivas en el sistema jurídico privado colombiano puede equipararse a dar un salto al vacío, como consecuencia de la ausencia de normas legales generales que regulen el tema y la escasa jurisprudencia civil sobre la materia.

Se aspira, sin embargo, indagar y presentar el tema a partir de una breve consideración sobre el postulado de la autonomía de la voluntad privada, su constatación o negación en los contratos de adhesión, la llamada justicia contractual, la teoría del abuso del derecho como fundamento último del rechazo al clausulado abusivo y la recepción de la teoría de la nulidad de la cláusula abusiva en la jurisprudencia civil colombiana.

Cabe advertir que la temática que se ensaya no es novedosa en el derecho comparado, en especial, en el denominado «Derecho del Consumo» y por lo mismo, en el amplio campo de la protección jurídica de los consumidores y usuarios en las Directivas de la Unión Europea y en las normativas legales internas de los países Europeos.

Igualmente, debemos destacar que en el derecho patrio, si bien no existe de manera general un régimen legal sobre la problemática de las cláusulas abusivas o vejatorias, la jurisprudencia nacional, con apego al principio general de la prohibición del abuso del derecho, ha decidido brindar protección a la parte contratante afectada por un acuerdo que finalmente se juzgue como abusivo, declarando la nulidad absoluta de tal convención particular.

\section{Breve consideración sobre el principio de la autonomía de la voluntad privada.}

Si se entiende la autonomía de la voluntad privada como aquella facultad o poder que se reconoce a los particulares para autorregular su vida negocial, resulta fácil comprender que aquélla cobija la facultad de contratar o no contratar, escoger la persona con la cual se contrata, elegir el tipo de contrato ${ }^{39}$ que se utiliza, el medio o la forma de expresión, el contenido del negocio, o si se quiere, la configuración interna del contrato ${ }^{1}$.

La autonomía negocial de los particulares y la libertad contractual que supone el ejercicio de aquélla son reconocidas por la Constitución Política Colombiana de

\footnotetext{
${ }^{39}$ HINESTROSA, FERNANDO. Autonomía Privada y Tipicidad Contractual, conferencia publicada en Reflexiones de un Libre Pensador, Bogotá, Universidad Externado de Colombia, 2002, Págs.400 ó 411.
} 
manera amplia, certera y reiterada ${ }^{40}$, pero también se reconoce que tal autonomía de la voluntad particular no puede de un lado ejercitarse de manera abusiva ${ }^{41}$, y de otro lado, no es posible su ejercicio en contravía de los llamados límites generales de la misma -el bien común, a que alude la Carta Política-, que tradicionalmente se identifican con el orden público y las buenas costumbres.

En términos coloquiales, por virtud de la autonomía de la voluntad privada, podemos contratar, contraer matrimonio, adoptar, testar, reconocer hijos, y en fin, regular nuestra actividad negocial con miras a satisfacer distintas necesidades individuales y colectivas.

Ciertamente, toda declaración de voluntad orientada a la creación, modificación o extinción de relaciones jurídicas, es decir, todo negocio jurídico en particular, el contrato, representa el ejercicio de la autonomía de la voluntad privada y por lo mismo, de ninguna manera debe violar o transgredir normas imperativas, o principios de orden público, o desconocer las llamadas buenas costumbres, según se advierte con amplitud en el ordenamiento privado colombiano ${ }^{42}$.

Hace ya décadas se ha colocado en duda la existencia real de la autonomía privada en los llamados contratos de adhesión, porque en los mismos el adherente no puede discutir su contenido y simplemente se somete a las condiciones que impone su contraparte contractual, normalmente, representada en la parte económicamente poderosa que señala el clausulado del convenio en armonía con sus especiales intereses.

Como recuerda JORGE LÓPEZ SANTA MARÍA, desde los principios del siglo $\mathrm{XX}$ se escuchan voces hostiles frente al reconocimiento de la naturaleza contractual en los llamados «contratos de adhesión», lo que incluso generó la doctrina o tesis anti contractual liderada por los eminentes juristas DUGUIT y HAURIOU, quienes acuñaron la expresión de que «los contratos de adhesión no tienen de contrato sino el nombre» 43 .

Además el contrato, como expresión de esa autonomía privada, debe armonizar y tutelar los derechos fundamentales de los contratantes, pues de lo contrario,

\footnotetext{
${ }^{40}$ Constitución Política arts.1, 2, 14, 16, 38, y 333 entre otros.

${ }^{41}$ Constitución Política art.95 numeral $1^{\circ}$.

${ }^{42}$ Código Civil arts. 16, 1518, 1519, 1521, 1523, 1524, 1525. Código de Comercio arts.822, 899.

${ }^{43}$ JORGE LÓPEZ SANTA MARÍA. Cláusulas Contractuales Abusivas y Derecho del Consumidor. Instituciones Modernas de Derecho Civil, Editorial Jurídica ConoSur Ltda., Santiago de Chile. 1996, Págs.424yss.
} 
cualquier desconocimiento o vulneración o atentado contra los derechos fundamentales a través de pactos contractuales pueden ser neutralizados por vía de la acción de tutela que ejercite cualquiera de los contratantes que sea afectado por una cláusula contenida en el contrato y que notoriamente desconozca o violente un derecho fundamental.

El art.86 parte final de la Carta Política regula la llamada tutela contra particulares y con fundamento en tal norma superior, se conocen varios pronunciamientos de la jurisdicción constitucional, orientados a la tutela de derechos fundamentales vulnerados o desconocidos con ocasión de la celebración de contratos privados, en los que una de las partes abusa de su contraparte contractual, bien por la imposición de cláusulas abusivas o bien, por el ejercicio abusivo de ciertos derechos derivados del contrato ${ }^{44}$.

Comentando el tema, el experto Constitucionalista Alexei Julio Estrada enseña: «...Entonces es debido a la condición de contratos de adhesión que tienen este tipo de convenios y a la consiguiente limitación de la autonomía de la voluntad de una de las partes contratantes, que se justifica una aplicación reforzada del principio de la buena Je contractual en beneficio de la parte más débil...» ${ }^{45}$.

Por lo demás, el principio de la buena fe contractual, exigible en el ámbito de la contratación privada y pública, ha servido con frecuencia como fundamento para tutelar los intereses de los contratantes en situaciones de indefensión o subordinación que se traducen en notorios desequilibrios económicos entre las partes contratantes; buena fe contractual que es frecuente reclamar aparejada con la prohibición de abuso del derecho, que también sirve de soporte a reclamos de una verdadera reciprocidad y conmutatividad de las obligaciones surgidas de convenio.

\section{De las cláusulas abusivas. Su regulación en el derecho comparado. Ausencia normativa en el derecho colombiano}

\footnotetext{
${ }^{44}$ Véase entre otras muchas las siguientes sentencias de tutela T-533/96, T-059/97, T-1 17/97, SU-039/98. En esta última, a propósito, referida a un contrato de medicina prepagada se dijo lo siguiente: «...El contrato de servicios de medicina prepagada reúne las características de ser bilateral, oneroso, aleatorio, principal, consensual y de ejecución sucesiva en los términos del Código Civil y surge al mundo jurídico como un contrato de adhesión, según el cual las partes contratantes se obligan mutuamente a través de cláusulas y condiciones que no son discutidas libre y previamente, sino preestablecidas por una de las partes y sobre las cuales la otra expresa su aceptación o su rechazo».

${ }^{45}$ ESTRADA, Alexei Julio. La Eficacia de los Derechos Fundamentales entre Particulares. Bogotá: Universidad Externado de Colombia, año 2000. Pág. 286.
} 
La moderna concepción del contrato como instrumento dinamizador de las relaciones económicas, coloca su acento en la protección de la parte débil del contractual, para procurar la justicia en el contrato, todo como respuesta a la notoria y frecuente circunstancia de desequilibrio económico entre los contratantes que ha conducido y conduce a la imposición de cláusulas abusivas o vejatorias, que son condenadas o rechazadas por la jurisdicción.

En otros términos: La autonomía privada, por ser tal, no hace automáticamente justo el contrato. En la sociedad actual -como lo explica el profesor Edgar Cortés- las reglas aplicables a los contratos se encuentran en una serie de fuentes que no se agotan en las disposiciones del Código Civil; es evidente que quien quiera hoy interpretar un contrato no puede tomar como único punto de referencia el Código, como tampoco puede, y es consecuencia de lo anterior, limitarse a buscar en la autonomía privada o autonomía de la voluntad con sus tradicionales límites y cargas, la respuesta última para desentrañar las verdaderas funciones y utilidades del mismo. La nueva concepción de la libertad contractual es el resultado de una transformación social visible y manifiesta que hace que tal libertad sea una forma vacía en la medida en que no se integre con una situación de paridad social y económica de los contratantes, y que obliga además a construir un sistema de tutela de los sujetos débiles frente a los posibles abusos por parte de quien se encuentra en una posición de dominación o de fuerza ${ }^{46}$.

A propósito: la disciplina de las cláusulas abusivas constituye el paradigma de la protección a la parte débil en el Derecho de Contratos moderno. El señalado instrumento de las cláusulas abusivas es, en primer término, una protección formal pues pone un límite en el proceso de formación del contrato. Ya la literatura jurídica clásica era consciente y estaba advertida sobre la necesidad de juntar el concepto de justicia con la forma jurídica del contrato y reconocía en el control judicial sobre el contenido del contrato y en las normas imperativas, las técnicas orientadas a compensar la ausencia o la desequilibrada distribución del poder contractual.

Hoy en día no es suficiente la igualdad formal de los contratantes, ni la presunta libertad contractual que se ejercita al momento de celebrar un contrato. La igualdad y libertad entendidas formalmente -como en la época de la codificación decimonónica-no satisfacen las aspiraciones de justicia material y equilibrio

\footnotetext{
${ }^{46}$ Edgar Cortés. Fuentes del Derecho, Fuentes del Contrato y Justicia Contractual El ejemplo de las cláusulas abusivas. Ensayo del autor citado, profesor del suscrito en la Maestría de Responsabilidad Civil y del Estado, cursada en la UNIVERSIDAD EXTERNADO DE COLOMBIA, 2002-2003, Pág. 1 y 2.
} 
económico en las relaciones contractuales del presente, caracterizadas por la globalización en el tráfico y producción de bienes y servicios.

La moderna visión sobre el contrato supone examinar materialmente el equilibrio económico entre las partes, es decir, no sólo considerar formalmente la igualdad entre contratantes, sino que ponderación apunta a indagar sobre la igualdad real entre las partes del contrato, que se traduce, verbi gratia, en igualdad frente a la información, igualdad de recursos económicos, igualdad en la participación en el mercado, igualdad de medios para la explotación de una industria etc., de tal suerte que en situaciones de desigualdad, el juez puede corregir tal estado de cosas, más aún en presencia de las llamadas cláusulas abusivas que surgen a propósito de la desigualdad material interpartes del contrato, lo que facilita la imposición unilateral y a veces estandarizada de cláusulas contractuales que implican ventajas notorias a favor de la parte fuerte del contrato, es decir, de quien predispone el contenido del negocio.

Cabe destacar que las cláusulas abusivas generalmente se incardinan en la contratación masiva o estandarizada con consumidores o usuarios; pero también se identifica su presencia en cualquier tipo de contrato, como se reconoce al unísono por la doctrina y la jurisprudencia.

\section{Derecho comparado}

La Directiva Europea 13/93 relativa a las cláusulas abusivas en los contratos con los consumidores dice que «en los contratos celebrados entre el consumidor y el profesional, que tengan por objeto la cesión de bienes o la prestación de servicios, se consideran abusivas las cláusulas que contrariando la buena fe, determinan a cargo del consumidor un desequilibrio significativo de los derechos y de las obligaciones derivadas del contrato».

Como dice el profesor EDGAR CORTES $^{47}$, de la citada normativa europea se vislumbran dos parámetros para determinar cuándo una cláusula es abusiva; el primero, el desequilibrio contractual, que se mide teniendo en cuenta el segundo, es decir, la buena fe.

En consecuencia, la buena fe o comportamiento leal de las partes constituye un criterio importante para valorar la abusividad de la cláusula.

\footnotetext{
${ }^{47}$ CORTES, EDGAR. Op. cit. pág. 16.
} 
En Italia, la Directiva Europea fue incorporada en el Código Civil como artículo 1469 bis, adoptando una cláusula general de la abusividad que la define, pues «es evidente que una más detallada y compleja enunciación del supuesto de hecho general de vejatoriedad, por cuanto pueda ser detallada, no está, por su propia naturaleza, en capacidad de agotar la múltiple y compleja fenomenología de hipótesis que se pueden conducir, abstractamente, al seno de la cláusula general, y corre el riesgo de convertirse en una previsión sustancialmente inútil o en una restricción injustificada del alcance aplicativo de la misma cláusula.

La noción de desequilibrio significativo, que hace parte de la definición, se presenta pues como una noción de contenido indeterminado, y es el juez el llamado a verificar, cada vez, su presencia, teniendo en cuenta los criterios normativos presentes» ${ }^{48}$.

En Francia, se adoptó la Directiva por medio de la Ley 95-96 del primero de febrero de 1995. Con todo, en Francia ya existía la Ley 78-23 del 10 de enero de 1978, que regulaba los derechos del consumidor y establecía que una cláusula era abusiva si reunía dos condiciones: El abuso de poder económico y la presencia de una ventaja excesiva. La Ley del 1995, combina el criterio de la Directiva Europea con la práctica jurisprudencial francesa y define como abusivas las cláusulas que tienen por objeto, o producen el efecto de crear en detrimento del consumidor o del no profesional, un desequilibrio significativo entre los derechos y obligaciones de las partes del contrato, dejando como elemento central el criterio del desequilibrio significativo, sin mención a la buena fe que se entiende subyacente en todo el sistema.

En Alemania, desde 1976 se había disciplinado el tema de las condiciones generales del contrato, en el ABG Gesetz, que establece un control judicial del contrato que con violación del principio de buena fe, perjudica en medida inadecuada al adherente. El derecho Alemán tiene como elemento cardinal para determinar la abusividad de una cláusula, el principio de buena fe sin que se hable de aprovechamiento del poder económico; así pues, la respuesta a la justicia en los contratos, en términos de no abusividad, pasa en Alemania a través del principio de buena fe o corrección.

En Inglaterra, para acondicionar la Directiva Europea al sistema interno, se dictó en 1994 el Unfair Terms in Consumer Contracts Regulations, que constituye una

\footnotetext{
${ }^{48}$ TROJANO, S. Citado por Edgar Cortés.
} 
novedad, pues, hasta entonces, la Ley inglesa sólo había considerado las cláusulas limitativas de responsabilidad para limitar en algunos casos la posibilidad de hacerlas valer; hay que aclarar, sin embargo, que en Inglaterra no existe una doctrina sobre el abuso del derecho. Una cláusula se define como inicua si «contrary to the requirements of good Faith, cause a significant imbalance in the parties rights and obligations under the contract to the detriment of the consumera $^{49}$. La buena fe, que es un concepto importado del «Civil Law», se hace presente y se prueba teniendo en cuenta varios factores: La posición contractual de las partes; cualquier influencia ejercida sobre el consumidor para aceptar la cláusula; el que los bienes o servicios hayan sido suministrados o vendidos con base en una orden específica; la medida en la que el vendedor ha obrado fairly and equitably.

En Argentina la Ley de Defensa del Consumidor, es decir, la Ley 24240, en el punto de cláusulas abusivas, en su art.37 curiosamente bautizado «de los términos abusivos y cláusulas ineficaces», no define las señaladas cláusulas, sino que manifiesta que se tendrán por no convenidas algunas cláusulas como las de limitación de responsabilidad, las que impliquen renuncia o restricción de derechos al consumidor, $Y$ las que inviertan la carga de la prueba en perjuicio del consumidor. En el mismo país, el Decreto 1798 de 1994, reglamentario de la citada Ley, se ocupó de definir las cláusulas abusivas diciendo que son aquellas que afecten inequitativamente al consumidor y usuario en el cotejo entre los derechos y obligaciones de ambas partes.

Brasil, en su Código de Defensa del Consumidor dice que las cláusulas abusivas son las que establezcan obligaciones consideradas inequitativas, que pongan al consumidor en desventaja exagerada o sean incompatibles con la buena fe o la equidad, y agrega que se presume exagerada la ventaja que ofende los principios fundamentales del sistema jurídico al que pertenecen, o que restringe derechos $u$ obligaciones fundamentales inherentes a la naturaleza del contrato, de modo que amenace el objeto o el equilibrio contractual, o en fin, cuando se demuestra excesivamente onerosa para el consumidor.

En Costa Rica, la ley 7472 de 1994, para la promoción de la competencia y defensa del consumidor, en lo tocante a las cláusulas abusivas, no las define pero establece dos enumeraciones de casos o situaciones que se consideran como pactos abusivos y se sancionan con la nulidad absoluta.

\footnotetext{
${ }^{49}$ Contrario a los requerimientos de la buena Je, causa un desbalance significativo en los derechos y obligaciones de las partes ante el contrato, en detrimento del consumidor.
} 
En Chile, la ley 19496 de 27 de diciembre de 1999, relacionada con los derechos de los consumidores, sigue el sistema de Costa Rica, pues, sin definir en qué consisten las cláusulas abusivas, en su art. 16 enumera una serie de cláusulas que no producirán efecto alguno.

Algo similar ocurre en el Ecuador donde la Ley Orgánica de Defensa del Consumidor del 4 de julio de 2000, hace un listado de cláusulas prohibidas que son calificadas como nulas de pleno derecho y no producirán efecto alguno.

\section{La situación en derecho colombiano}

Si bien en el derecho positivo colombiano no existe una reglamentación general sobre las cláusulas abusivas, -salvo la regulación del artículo 133 de la ley 142 de 1994 relacionada con contratos de prestación de servicios públicos- como si existe en el derecho comparado, no cabe duda que la presencia e inclusión de tales cláusulas es rechazada por ineficaz -nulidad absoluta- por la jurisdicción.

En efecto, en época reciente la Sala de Casación Civil y Agraria de la Corte Suprema de Justicia, en sentencia de 2 de febrero de 2001, califica como nula absolutamente una cláusula abusiva que fuera «pactada» en un contrato de seguro, y sobre el tema, entre otras cosas, se dice:

«...Toda vez que este tipo de cláusulas restrictivas, como la aquí invocada por la censura -calificadas como abusivas por la doctrina y la legislación comparadas-, eran nulas absolutamente por mandato del numeral primero del artículo 899 del código de comercio, hoy ineficaces según el literal (a) del numeral $2^{\circ}$ del art.184 del Decreto 663 de 1993, en concordancia con el inciso $2^{\circ}$ del numeral $4^{\circ}$ del art. 98 y el numeral $3^{\circ}$ del art. 100 de la misma normatividad, en cuanto violan disposiciones que como los arts. 1077 y 1080 del estatuto mercantil son imperativas... cumple anotar que tratándose de negocios jurídicos concluidos y desarrollados a través de la adhesión a condiciones generales de contratación como sucede con el de seguro, la legislación comparada y la doctrina universal de tiempo atrás han situado en primer plano la necesidad de delimitar su contenido particularmente para excluir aquellas cláusulas que sirven para proporcionar ventajas egoístas a costa del contratante individual... lo abusivo o despótico de este tipo de cláusulas que pueden estar presentes en cualquier contrato y no solo en los de adhesión o negocios tipo se acentúa aún más si se tiene en cuenta que el asegurador las inserta dentro de las condiciones generales del contrato...». 
Cabe advertir con todo, que la novísima -entre nosotros- doctrina de las cláusulas abusivas cuya nulidad absoluta puede y debe ser declarada por el juez, encuentra soporte normativo en la teoría del abuso del derecho consagrada desde antaño por el Código Civil en el Art. $8^{\circ}$ de la Ley 153 de 1887, aún vigente entre nosotros, y que ha sido la fuente de figuras tan importantes en el ámbito del derecho civil colombiano, tales como: el abuso del derecho, el enriquecimiento sin causa, la imprevisión y el fraude a la Ley.

La doctrina chilena -muy de recibo entre nosotros por la similitud extrema del Código Civil- representada por la profesora PAULINA VELOSO VALENZUELA, en estudio reciente sobre las cláusulas abusivas, nos enseña:

«...Los contratos de adhesión -contrapuestos a los contratos libremente discutidos o por negociación- son aquellos cuyas cláusulas son dictadas o redactadas por una sola de las partes. La otra se limita a aceptarlas en bloque adhiriendo a ellas.

El elemento distintivo de la adhesión, en concepto del profesor Jorge López Santa María, es el desequilibrio del poder negociador de los contratantes. El fenómeno de la adhesión puede ocurrir en una contratación aislada, fruto simplemente del mayor poder de una de las partes, acompañado, muchas veces, de la negligencia, ligereza o ignorancia de la otra, o bien en la contratación masiva donde la «empresa» impone un texto previamente redactado e impreso al «consumidor». La adhesión en la contratación masiva constituye normalmente lo que se denomina condiciones generales de contratación, también llamado contrato tipo...Elementos distintivos de estas cláusulas son:

1. Normalmente derogan las normas dispositivas o los usos que reglamentan el contrato correspondiente,

2. Son cláusulas que contrarían la buena fe contractual, 3. Atenían a la reciprocidad de las prestaciones, esto es, entrañan usualmente un notorio desequilibrio de ellas y consiguientemente vulneran la justicia conmutativa...» (PAULINA VELOSO VALENZUELA. Cláusulas abusivas, Págs. 445 y 447, en la obra colectiva Instituciones Modernas de Derecho Civil, Santiago de Chile, 1996).

La doctrina nacional en obra jurídica excelsa escrita por nuestro maestro ERNESTO RENGIFO GARCÍA, trae a explicación el caso de las cláusulas abusivas en la contratación con artistas, intérpretes y ejecutantes, y refiere el caso judicial decidido por Tribunal de Arbitramento entre SONOLUX y AURA CRISTINA GEITHNER, laudo que encontró el abuso de la empresa al señalar mediante cláusula una 
exclusividad por largo tiempo sin contraprestación alguna, advirtiendo que si bien es cierto una cláusula de exclusividad per se no significa que sea abusiva, «no se concibe que una persona entregue su futuro artístico a otra, vinculándose a ésta por un lapso más o menos prolongado de tiempo, sin esperar, a su turno, una obligación de su contraparte que compense el sacrificio que se efectúa» (ERNESTO RENGIFO GARCÍA. Del Abuso del Derecho al Abuso de la Posición Dominante, Universidad Externado de Colombia, 2002, Págs. 316 y 317).

En resumen: En Colombia no existe un régimen legal general sobre las cláusulas abusivas, su referencia legislativa es aislada, por ejemplo; la regulada en la ley de servicios públicos domiciliarios, o el caso del Estatuto Orgánico del Sistema Financiero (Decreto 663 de 1993 art .97), donde se sugiere la abstención de convenir cláusulas que puedan alterar el equilibrio del contrato.

Con todo, creemos que en el Sistema Jurídico Colombiano, muy a pesar de la orfandad legislativa general sobre la materia, existen los principios generales de la buena fe y abuso del derecho, que en conjunto sirven de valiosas herramientas jurídicas para definir los casos o situaciones de pactos abusivos, con la consecuente reparación del perjuicio a cargo del predisponente del convenio que se juzgue como abusivo. 